\title{
Expression of Insulin-Like Growth Factor 1 and Insulin-Like Growth Factor 1 Receptor is Associated with the Favorable Clinicopathologic Parameters in Small Intestinal Carcinomas
}

\author{
Hyung Chan Shin ${ }^{a}$ Young Kyung Bae ${ }^{a}$ Mi Jin Gu $u^{a}$ Eun Sun Jung ${ }^{b}$ \\ Young-Ha Oh ${ }^{c}$ The Korean Small Intestinal Cancer Study Group \\ ${ }^{a}$ Department of Pathology, Yeungnam University College of Medicine, Daegu, ${ }^{b}$ Department of Pathology, \\ The Catholic University College of Medicine, and ${ }^{\mathrm{C}}$ Department of Pathology, Hanyang University College of \\ Medicine, Seoul, Korea
}

\section{Key Words}

Small intestine $\cdot$ Carcinoma $\cdot$ Immunohistochemistry . Insulin-like growth factor system · Insulin-like growth factor $1 \cdot$ Insulin-like growth factor 1 receptor

\begin{abstract}
Objective: The insulin-like growth factor (IGF) system has been known to play a critical role in tumor development and progression in many human cancers. However, the role of the IGF system in small intestinal carcinoma (SIC) has not been studied yet. Methods: We evaluated the expression of IGF1 and IGF1 receptor (IFG1R) in a total of 194 cases of SIC. Results: IGF1 expression was associated with well/moderate differentiation, better survival, lower pT, lower stage and no lymph node metastasis. IGF1R was more diffusely and strongly expressed in tumors with lower $\mathrm{PT}$ and lower stage. Conclusions: IGF1 and IGF1R expression is associated with favorable clinicopathologic parameters and may involve early carcinogenesis of SICs. Target therapy for the IGF1R signaling pathway may not have a major therapeutic role in treating SIC.

Copyright $\odot 2013$ S. Karger AG, Basel
\end{abstract}

(c) 2013 S. Karger AG, Basel

$1015-2008 / 13 / 0805-0265 \$ 38.00 / 0$

\section{Introduction}

Despite the small intestine being the largest part of the digestive system, primary small intestinal carcinoma (SIC) occurs in less than $5 \%$ of gastrointestinal malignancies [1]. The reason for this low incidence still remains unknown. SIC is usually detected at an advanced stage due to its rareness and nonspecific symptoms [2]. In spite of the many studies conducted on carcinogenesis of SIC, it is not yet clearly defined.

The insulin-like growth factor (IGF) system plays a critical role in the growth and development of many normal tissues [3, 4]. IGF1 receptor (IGF1R) contains a cytoplasmic tyrosine kinase domain and binds both IGF1 and IGF2 $[5,6]$. This interaction triggers a signaling cascade leading to cellular proliferation and inhibition of apoptosis [7]. Thus, many researchers suggested that the status of IGF1R expression in tumors may play a key role in clinical and therapeutic strategy. Previous studies have shown that an increased expression of IGF or its family is associated with the grade and prognosis of many solid tumors, but its prognostic value is controversial depending on the sites and researchers $[3,5,6,8,9]$. To the best of our knowledge, this is the first report on the expression of IGF1 and IGF1R in SIC.

\section{KARGER}

E-Mail karger@karger.com www.karger.com/pat
Mi Jin $\mathrm{Gu}, \mathrm{MD}$

Department of Pathology

Yeungnam University College of Medicine

170, Hyeonchung-ro, Nam-gu, Daegu, 705-717 (Korea)

E-Mail mjgu@yu.ac.kr 

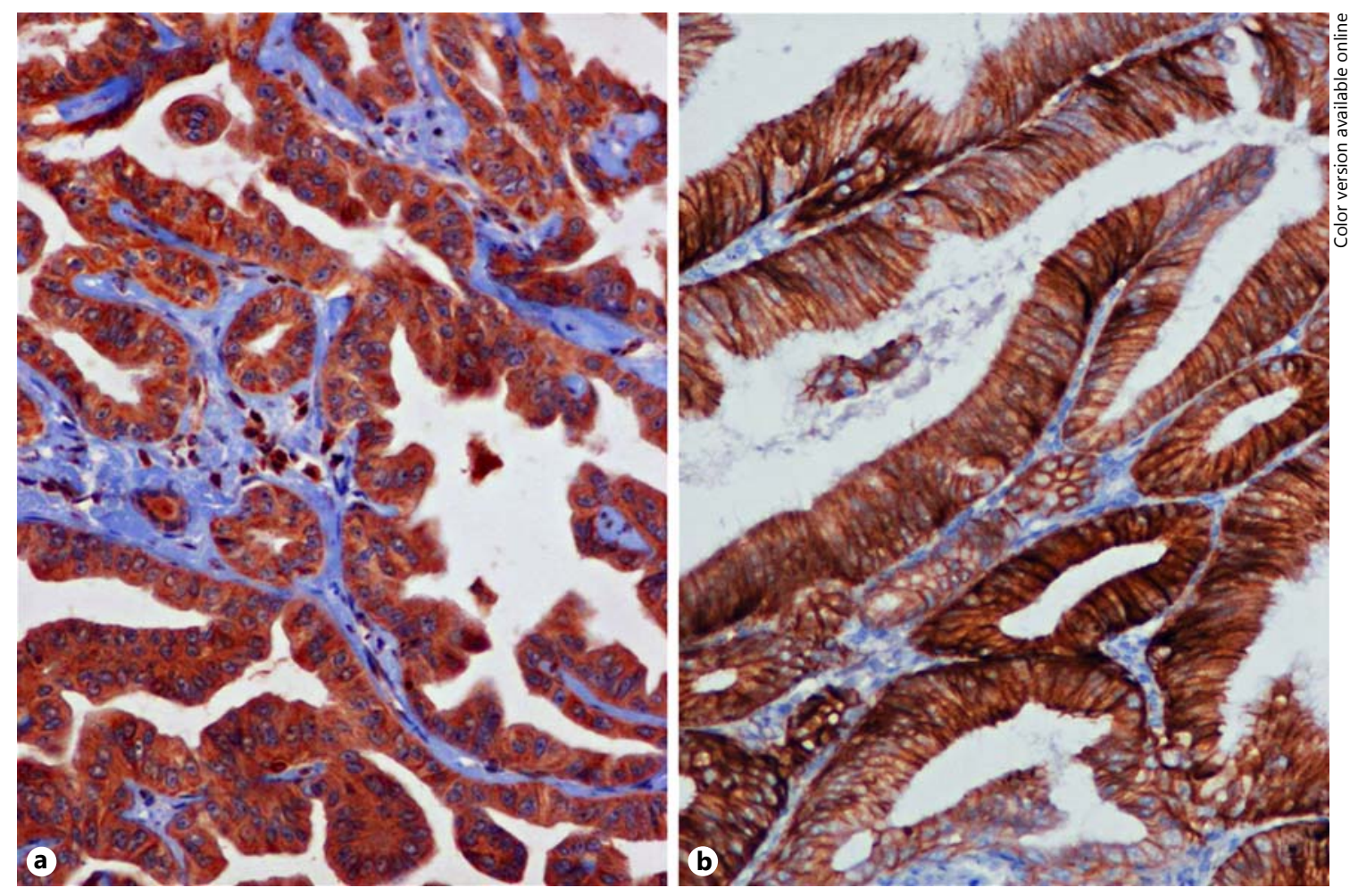

Fig. 1. Method 1 (strong positive in $>75 \%$ of tumor cells): tumor cells exhibited diffuse strong positivity for IGF1 (a) and IGF1R (b).

\section{Materials and Methods}

\section{Specimen}

A total of 194 SIC cases were collected from the Pathology Department of 20 hospitals in Korea. Primary carcinomas arising from the duodenum, jejunum and ileum were included and the primary ampulla of the Vater carcinoma or extension from other gastrointestinal carcinomas was excluded. The histology of all tumor specimens was initially evaluated by gastrointestinal pathologists from each institution and finally reviewed by 2 pathologists (M.J. Gu, Y.K. Bae). Reviews of medical records and pathologic reports were used to identify patient's age, sex, most recent follow-up, as well as survival status and presence or absence of disease related to the occurrence of SIC. The study was approved by the Human Ethics Review Board of each institution which participated in the Korean Small Intestinal Cancer Study Group.

\section{Tissue Microarray}

Four 1-mm cores were obtained from the most representative tumor area of each case and arrayed in a new recipient block: two or three SICs, one metastatic lymph node and one normal intestinal mucosa. In total, 7 tissue microarray blocks were made with 194 SICs. The controls were normal liver, kidney, spleen, placenta and breast cancer.

\section{Immunohistochemistry}

After deparaffinization and rehydration, $4-\mu \mathrm{m}$ sections were immunostained for IGF1 (1:50, Clone: ab9572; Abcam, Cambridge, UK) and IGF1R (Predilution, Clone: G11; Ventana Medical Systems, Tucson, Ariz., USA). The staining was performed on the Ventana Benchmark ${ }^{\circledR}$ platform automated slide stainer (Ventana Medical Systems) using the onboard heat-induced epitope retrieval method in high $\mathrm{pH} \mathrm{CC} 1$ buffer $\left(99^{\circ} \mathrm{C}, 1 \mathrm{~h}\right)$. The staining was visualized using the iView ${ }^{\mathrm{TM}}$ DAB detection Kit (Automated Benchmark ${ }^{\circledR}$; Ventana Medical Systems), which involved a hydrogen peroxide substrate and a $3.3^{\prime}$-diaminobenzidine chromogen solution. The slides were subsequently counterstained with hematoxylin. We used two methods to evaluate the expression. Method 1: diffuse strong cytoplasmic staining for IGF1 staining and diffuse strong membranous staining for IGF1R staining in $>75 \%$ of tumor cells (fig. 1); method 2: staining of $>10 \%$ tumor cells with any intensity (fig. 2 ).

\section{Statistical Analysis}

Statistical comparisons were performed using SPSS version 19.0 (SPSS Inc., Chicago, Ill., USA). The $\chi^{2}$ test and Fisher's exact test were performed to examine associations between clinicopathologic parameters and IGF1 or IGF1R expression. Overall patient survival was defined as the time from surgical resection of SICs to death of patients or last follow-up. The survival rate was calculated by the Kaplan-Meier method. A comparison of the survival rate with regard to clinicopathologic parameters was 

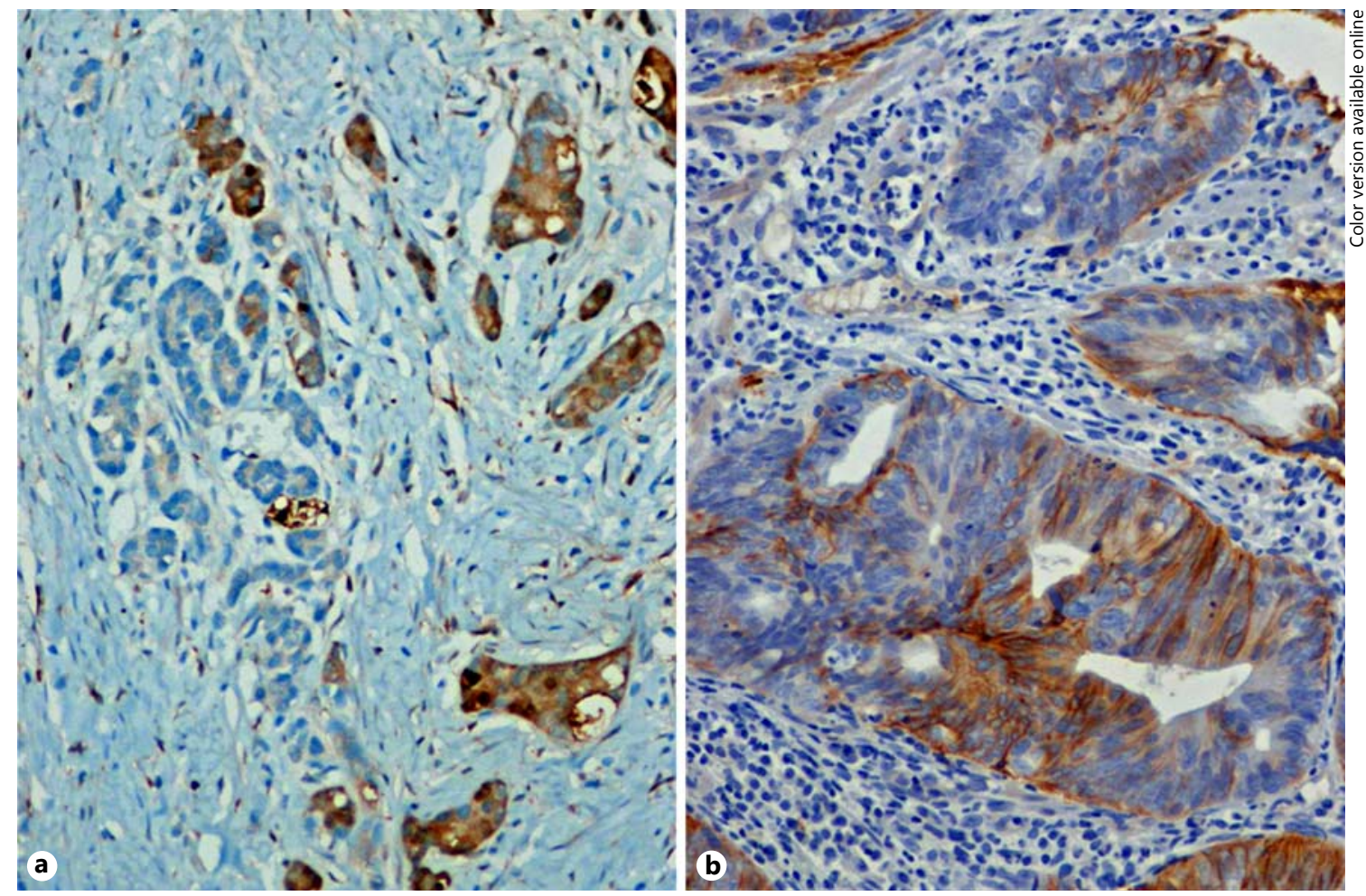

Fig. 2. Method 2 (staining of $>10 \%$ tumor cells with any intensity): tumor cells stained focally for IGF1 (a) and stained weakly and focally for IGF1R (b).

performed by the log-rank test. For multivariate analysis, the Cox proportional hazards model was performed. A p value $<0.05$ was considered statistically significant.

\section{Results}

\section{Characteristics of Patients}

One hundred and twenty-one male and 73 female patients with a median age of 58.9 years (range 23-86) were included for this study. Tumors were located in the duodenum in 105 cases (54.1\%), the jejunum in 59 cases $(30.4 \%)$ and the ileum in 30 cases $(15.5 \%)$. By growth feature, 35 cases were polypoid $(18.0 \%), 12$ cases nodular (6.2\%), 8 cases not available (4.1\%) and 139 cases infiltrative $(71.6 \%)$. Tumor size ranged from 1 to $16 \mathrm{~cm}$ (mean 4.37). Histologic subtypes included 176 adenocarcinomas $(90.7 \%), 9$ mucinous carcinomas (4.6\%), 4 signet ring adenocarcinomas $(2.1 \%)$, and 5 undifferentiated carcinomas $(2.6 \%)$. Vascular and lymphatic invasions were observed in $51(26.3 \%)$ and 95 (49.0\%) cases, respectively. Pancreas invasion was found in 68 cases $(35.1 \%)$. Eighty- nine $(50.9 \%)$ cases showed metastasis to the regional lymph node. Retroperitoneal tumor seeding was observed in 14 cases. pT staging showed pTis in 4 cases, pT1 in 7 cases, pT2 in 9 cases, pT3 in 63 cases, and pT4 in 111 cases. These were reclassified into pT2 (including pTis, pT1 and pT2), pT3 and pT4, and the statistical significance was analyzed.

\section{Immunohistochemical Results}

Method 1 (diffuse strong positive in $>75 \%$ of tumor cells): overexpression of IGF 1 and IGF1R was observed in $30 / 176(17.0 \%)$ and 45/189 (23.8\%) cases (fig. 1), respectively. IGF1 overexpression was observed more often in tumors with lower $\mathrm{pT}$, lower $\mathrm{pN}$ and lower stage and was associated with better overall survival ( $\mathrm{p}=0.003$; fig. 3 ). IGF1R overexpression was evident in tumors with lower $\mathrm{pT}$ and lower stage.

Method 2 (staining of $>10 \%$ tumor cells with any intensity): expression of IGF1 and IGF1R was observed in $139 / 178(78.1 \%)$ and $126 / 187$ (67.4\%) cases (fig. 2), respectively. IGF1 expression was more frequently observed in tumors with usual adenocarcinoma and muci- 


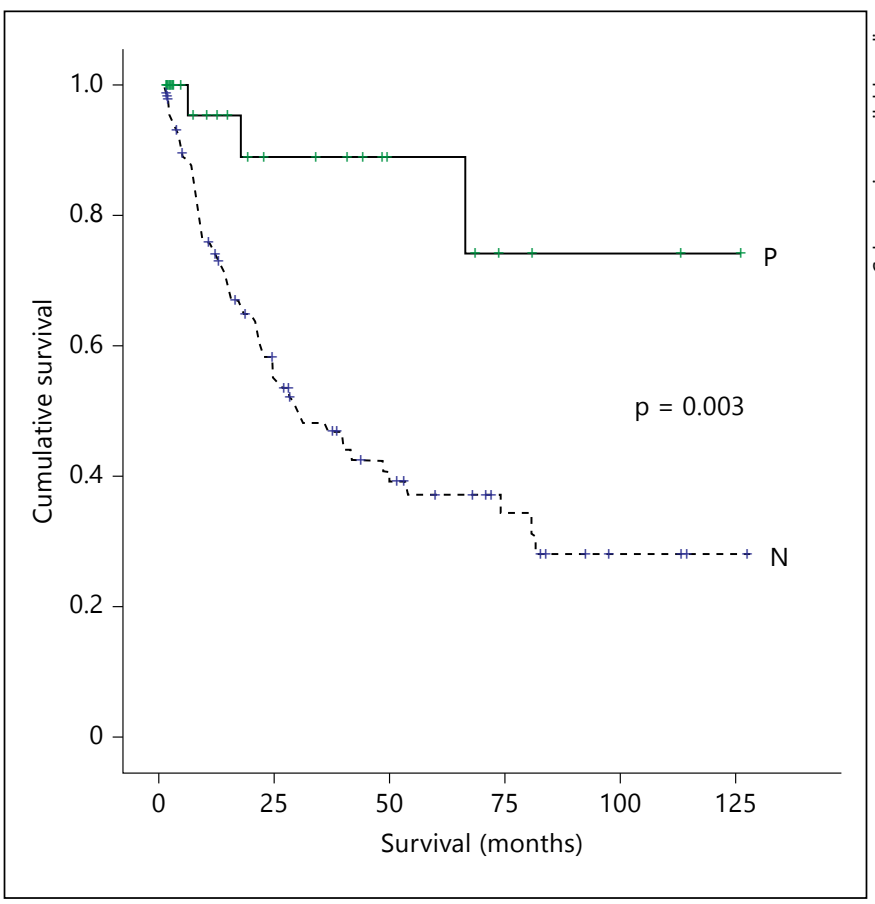

Fig. 3. Kaplan-Meier curve for overall survival for IGF1 expression. $\mathrm{P}=$ Positive; $\mathrm{N}=$ negative.

nous carcinoma, well/moderately differentiated adenocarcinoma, no lymphatic invasion, lower $\mathrm{pT}$, lower $\mathrm{pN}$, and lower stage and is associated with better overall survival $(\mathrm{p}=0.015)$. IGF1R expression was only related to histologic type (table 1,2).

By multivariate analyses for overall survival, lower $\mathrm{pT}$, lower $\mathrm{pN}$ and pancreas invasion was associated with better overall survival. Overexpression of IGF1 (diffuse strong positive in $>75 \%$ of tumor cells) was related to better overall survival ( $\mathrm{p}=0.024)$. IGF1R overexpression (diffuse strong positive in $>75 \%$ of tumor cells) was associated with better survival without statistical significance $(\mathrm{p}=0.084)$.

\section{Discussion}

IGF1 and its binding proteins have effects on cell proliferation, differentiation and the prevention of apoptosis through the activation of various intracellular signaling pathways, including the RAS/Raf/MAP kinase and phosphoinositide-3 kinase pathways [10-12]. IGF1R has significant potential as a therapeutic target for IGF1Rdriven cancers $[13,14]$. Inhibition of IGF1R was shown to be associated with a decrease in adhesion, invasion and metastasis of tumor cells and with an increase in tumor sensitivity for chemotherapy and radiation [15, 16]. Overexpression of IGF1R has been reported in a wide variety of human carcinomas, including breast cancer, gallbladder carcinoma, esophageal squamous cell carcinoma, prostate cancer, renal cell carcinoma, and colorectal carcinoma. However, its prognostic value is controversial depending on the sites of carcinoma [4, 17-22]. Many reports suggested that IGF1R expression correlated with poor survival in breast cancer $[18,23$, 24]. In contrast, $\mathrm{Fu}$ et al. [23] described that IGF1R mRNA expression was significantly higher in patients with favorable clinicopathologic parameters. In gallbladder cancer, tumors with less than $50 \%$ of IGF1R immunoreactions showed a significantly worse prognosis [19]. Schips et al. [22] described that IGF1 and IGF1R overexpression was not related to prognosis in renal cell carcinoma. In esophageal carcinoma, IGF1R overexpression was correlated with short survival and metastasis [20]. Hakam et al. [25] described that IGF1R is more frequently expressed in tumors with high grade and with high stage in colorectal carcinoma. However, Shiratsuchi et al. [4] suggested that IGF1 and IGF1R overexpression was not related to the prognosis of colorectal cancers. Nakamura et al. [26] reported that low IGF1R expression correlated with an increased risk of liver metastasis. The correlation between IGF1 or IGF1R overexpression and clinicopathologic parameters has been shown to be diverse, depending on the tumor sites and researchers. We used two different methods for evaluation, because there is no universally valid immunohistochemical scoring system for IGF1 and IGF1R expression. To the best of our knowledge, this research is the first study to evaluate IGF1 and IGF1R expression in a large number of SICs with clinicopathologic correlation. According to our results, IGF1 expression was associated with lower $\mathrm{pT}$, lower $\mathrm{pN}$ and lower stage, regardless of the staining intensity or proportion. On the other hand, IGF1R was more diffusely and strongly expressed in tumors with lower $\mathrm{pT}$ and lower stage. Those findings were also observed in previous studies of gallbladder and colorectal cancers [19, 26, 27], which suggests that the IGF system is involved at an early stage during carcinogenesis of SIC, and additional genetic alterations are necessary for metastasis or invasion and may not be related to cell proliferation, tumor progression and apoptosis. Therefore, target therapy for the IGF1R signaling pathway may not have a major therapeutic role in treating SIC. Although the selection of pa- 
Table 1. Comparison between clinicopathologic factors and IGF1 and IGF1R expression

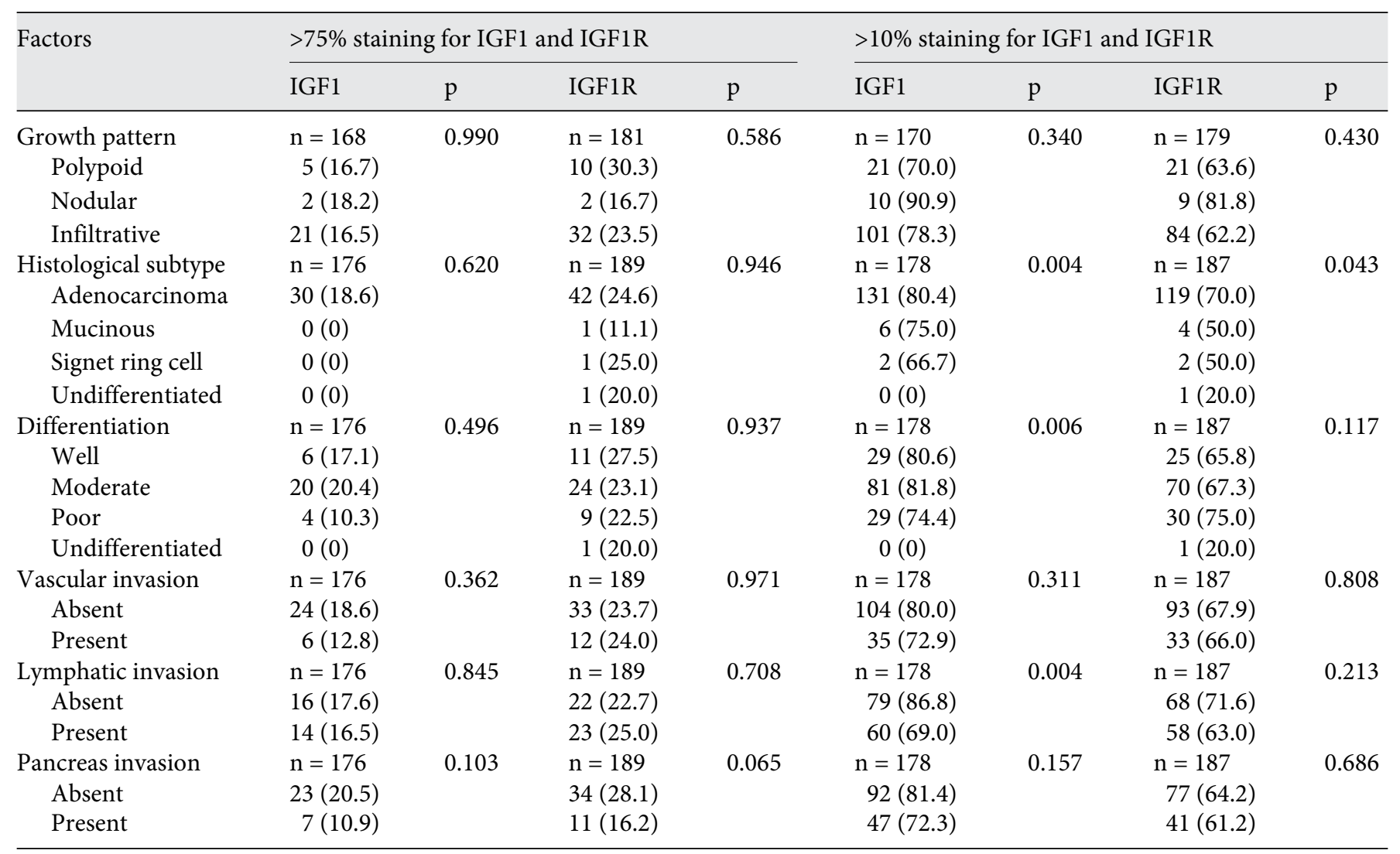

Figures in parentheses are percentages. $\mathrm{n}=$ Total number of cases analyzed.

Table 2. Comparison between pathologic stage and IGF1 and IGF1R expression

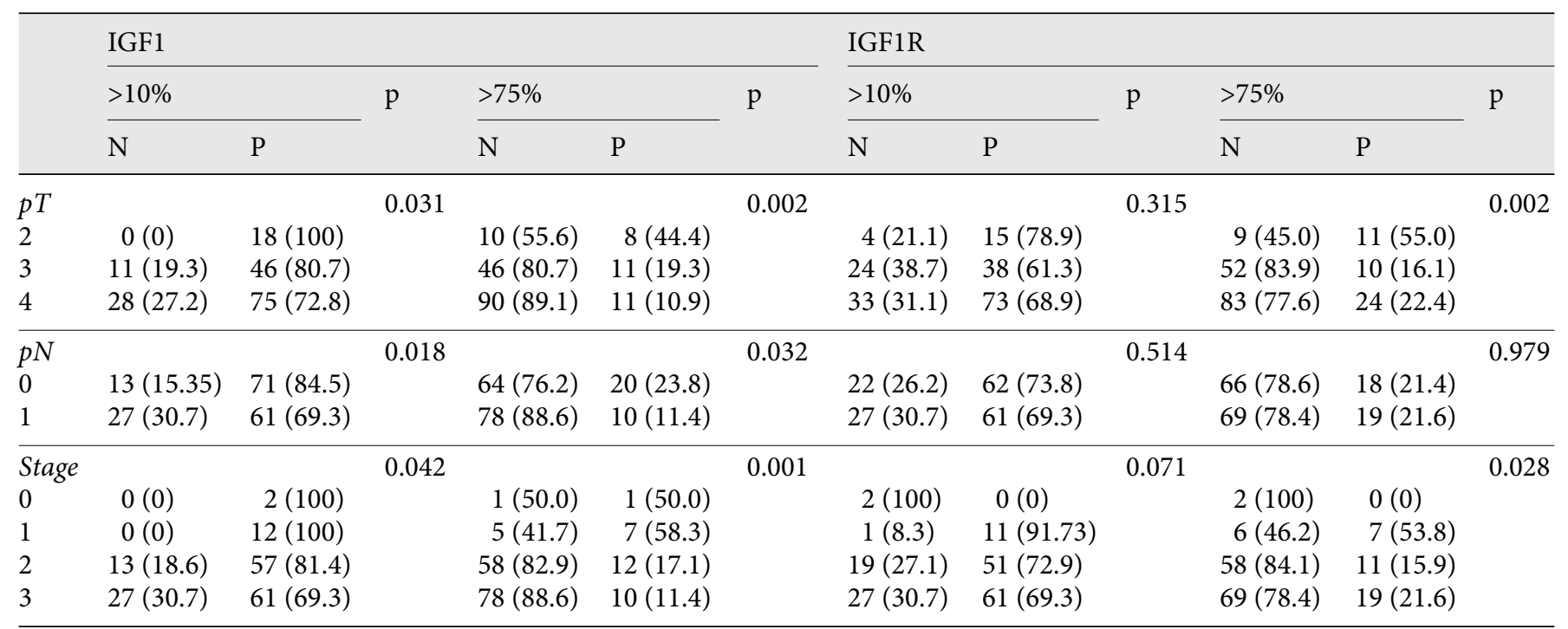

Figures in parentheses are percentages. $\mathrm{N}=$ Negative; $\mathrm{P}=$ positive. 
tients for clinical trials through the use of IGF1R immunohistochemistry has been suggested in many cancers, target therapy for the IGF1R signaling pathway may not have a major therapeutic role in treating SIC.

In summary, IGF1 expression was associated with favorable clinicopathologic parameters and better overall survival regardless of the staining intensity or proportion. For IGF1R, diffuse strong expression is related to favorable clinicopathologic parameters. The IGF system may play a role in early carcinogenesis of SIC, and additional genetic alterations are necessary for metastasis or invasion.

\section{Disclosure Statement}

The authors declare no conflicts of interest.

\section{References}

1 Warth A, Kloor M, Schirmacher P, Blaker H: Genetics and epigenetics of small bowel adenocarcinoma: the interactions of CIN, MSI, and CIMP. Mod Pathol 2011;24:564-570.

2 Chang HK, Yu E, Kim J, Bae YK, Jang KT, Jung ES, Yoon GS, Kim JM, Oh YH, Bae HI, Kim GI, Jung SJ, Gu MJ, Kim JY, Jang KY, Jun SY, Eom DW, Kwon KW, Kang GH, Park JB, Hong S, Lee JS, Park JY, Hong SM, Korean Small Intestinal Cancer Study Group: Adenocarcinoma of the small intestine. A multi-institutional study of 197 surgically resected cases. Hum Pathol 2010;41:1087-1096.

3 Janeway KA, Zhu MJ, Barretina J, Perez-Atayde A, Demetri GD, Fletcher JA: Strong expression of IGF1R in pediatric gastrointestinal stromal tumors without IGF1R genomic amplification. Int J Cancer 2010;127:27182722.

4 Shiratsuchi I, Akagi Y, Kawahara A, Kinugasa T, Romeo K, Yoshida T, Ryu Y, Gotanda Y, Kage M, Shirouzu K: Expression of IGF-1 and IGF-1R and their relation to clinicopathological factors in colorectal cancer. Anticancer Res 2011;31:2541-2545.

5 Steigen SE, Schaeffer DF, West RB, Nielsen TO: Expression of insulin-like growth factor 2 in mesenchymal neoplasms. Mod Pathol 2009;22:914-921.

6 Pantaleo MA, Astolfi A, Nannini M, Biasco G: The emerging role of insulin-like growth factor 1 receptor (IGF1r) in gastrointestinal stromal tumors (GISTs). J Transl Med 2010;8:117.

7 Braconi C, Bracci R, Bearzi I, Bianchi F, Sabato S, Mandolesi A, Belvederesi L, Cascinu S, Valeri $\mathrm{N}$, Cellerino R: Insulin-like growth factor (IGF) 1 and 2 help to predict disease outcome in GIST patients. Ann Oncol 2008;19:1293-1298.

8 Ahlen J, Wejde J, Brosjo O, von Rosen A, Weng WH, Girnita L, Larsson O, Larsson C: Insulin-like growth factor type 1 receptor expression correlates to good prognosis in highly malignant soft tissue sarcoma. Clin Cancer Res 2005;11:206-216.

9 Xie Y, Skytting B, Nilsson G, Brodin B, Larsson O: Expression of insulin-like growth factor-1 receptor in synovial sarcoma: association with an aggressive phenotype. Cancer Res 1999;59:3588-3591.

10 Werner H, Le Roith D: New concepts in regulation and function of the insulin-like growth factors: implications for understanding normal growth and neoplasia. Cell Mol Life Sci 2000;57:932-942.

11 Zhu MJ, Ou WB, Fletcher CD, Cohen PS, Demetri GD, Fletcher JA: KIT oncoprotein interactions in gastrointestinal stromal tumors: therapeutic relevance. Oncogene 2007; 26:6386-6395.

12 Braconi C, Bracci R, Cellerino R: Molecular targets in gastrointestinal stromal tumors (GIST) therapy. Curr Cancer Drug Targets 2008;8:359-366.

13 Tarn C, Rink L, Merkel E, Flieder D, Pathak H, Koumbi D, Testa JR, Eisenberg B, von Mehren M, Godwin AK: Insulin-like growth factor 1 receptor is a potential therapeutic target for gastrointestinal stromal tumors. Proc Natl Acad Sci USA 2008;105:8387-8392.

14 Chou A, Chen J, Clarkson A, Samra JS, Clifton-Bligh RJ, Hugh TJ, Gill AJ: Succinate dehydrogenase-deficient GISTs are characterized by IGF1R overexpression. Mod Pathol 2012;25:1307-1313.

15 Long L, Rubin R, Baserga R, Brodt P: Loss of the metastatic phenotype in murine carcinoma cells expressing an antisense RNA to the insulin-like growth factor receptor. Cancer Res 1995;55:1006-1009.

16 Turner BC, Haffty BG, Narayanan L, Yuan J, Havre PA, Gumbs AA, Kaplan L, Burgaud JL, Carter D, Baserga R, Glazer PM: Insulin-like growth factor-I receptor overexpression mediates cellular radioresistance and local breast cancer recurrence after lumpectomy and radiation. Cancer Res 1997;57:3079-3083.

17 Ouban A, Muraca P, Yeatman T, Coppola D: Expression and distribution of insulin-like growth factor-1 receptor in human carcinomas. Hum Pathol 2003;34:803-808.

18 Peiro G, Adrover E, Sanchez-Tejada L, Lerma E, Planelles M, Sanchez-Paya J, Aranda FI, Giner D, Gutierrez-Avino FJ: Increased insulin-like growth factor-1 receptor mRNA expression predicts poor survival in immunophenotypes of early breast carcinoma. Mod Pathol 2011;24:201-208.

19 Kornprat P, Rehak P, Ruschoff J, Langner C: Expression of IGF-I, IGF-II, and IGF-IR in gallbladder carcinoma. A systematic analysis including primary and corresponding metastatic tumours. J Clin Pathol 2006;59:202-206.
20 Imsumran A, Adachi Y, Yamamoto H, Li R, Wang Y, Min Y, Piao W, Nosho K, Arimura Y, Shinomura Y, Hosokawa M, Lee CT, Carbone DP, Imai K: Insulin-like growth factor-I receptor as a marker for prognosis and a therapeutic target in human esophageal squamous cell carcinoma. Carcinogenesis 2007; 28:947-956.

21 Cardillo MR, Monti S, Di Silverio F, Gentile V, Sciarra F, Toscano V: Insulin-like growth factor (IGF)-I, IGF-II and IGF type I receptor (IGFR-I) expression in prostatic cancer. Anticancer Res 2003;23:3825-3835.

22 Schips L, Zigeuner R, Ratschek M, Rehak P, Ruschoff J, Langner C: Analysis of insulin-like growth factors and insulin-like growth factor I receptor expression in renal cell carcinoma. Am J Clin Pathol 2004;122:931-937.

23 Fu P, Ibusuki M, Yamamoto Y, Hayashi M, Murakami K, Zheng S, Iwase H: Insulin-like growth factor-1 receptor gene expression is associated with survival in breast cancer: a comprehensive analysis of gene copy number, mRNA and protein expression. Breast Cancer Res Treat 2011;130:307-317.

24 Iqbal J, Thike AA, Cheok PY, Tse GM, Tan $\mathrm{PH}$ : Insulin growth factor receptor-1 expression and loss of PTEN protein predict early recurrence in triple-negative breast cancer. Histopathology 2012;61:652-659.

25 Hakam A, Yeatman TJ, Lu L, Mora L, Marcet G, Nicosia SV, Karl RC, Coppola D: Expression of insulin-like growth factor-1 receptor in human colorectal cancer. Hum Pathol 1999; 30:1128-1133.

26 Nakamura M, Miyamoto S, Maeda H, Zhang SC, Sangai T, Ishii G, Hasebe T, Endoh Y, Saito N, Asaka M, Ochiai A: Low levels of insulin-like growth factor type 1 receptor expression at cancer cell membrane predict liver metastasis in dukes' $\mathrm{C}$ human colorectal cancers. Clin Cancer Res 2004; 10:84348441.

27 Nosho K, Yamamoto H, Taniguchi H, Adachi Y, Yoshida Y, Arimura Y, Endo T, Hinoda Y, Imai K: Interplay of insulin-like growth factor-II, insulin-like growth factor-I, insulinlike growth factor-I receptor, COX-2, and matrix metalloproteinase-7, play key roles in the early stage of colorectal carcinogenesis. Clin Cancer Res 2004;10:7950-7957. 